\title{
Insulin like growth factor binding protein 7 (IGFBP7) expression is linked to poor prognosis but may protect from bone disease in multiple myeloma
}

Arnold Bolomsky ${ }^{1}$, Dirk Hose ${ }^{2}$, Martin Schreder ${ }^{1}$, Anja Seckinger², Susanne Lipp², Bernard Klein ${ }^{3}$, Daniel Heintel', Heinz Ludwig ${ }^{1}$ and Niklas Zojer ${ }^{1 *}$

\begin{abstract}
Background: Insulin like growth factor binding protein 7 (IGFBP7) is a secreted protein binding insulin like growth factor 1 (IGF-1), insulin, vascular endothelial growth factor A (VEGFA), and activin A. It antagonizes bone morphogenetic proteins and is involved in the tumour propagation of solid as well as haematological malignancies. Its role in multiple myeloma (MM) is not defined so far. We therefore aim here to investigate its prognostic and pathophysiological role in MM.

Methods: The clinical significance of IGFBP7 gene expression was investigated by gene expression profiling in two independent cohorts $(n=948)$ of newly-diagnosed MM patients. Methylation of the IGFBP7 promoter was analysed by pyrosequencing and treatment of MM cell lines with 5-aza-2-deoxycytidine. The impact of IGFBP7 on MM cells was studied by CCK-8 assay, BrdU assay and flow cytometry, respectively. IGFBP7 expression in bone marrow stromal cells (BMSCS) was studied by quantitative RT-PCR. For osteoblast development, immortalized and primary human BMSCs were cultured in osteogenic differentiation medium for 7-14 days in the presence of recombinant human IGFBP7 and/or activin A.

Results: Median IGFBP7 expression is significantly lower in CD138-purified plasma cells from individuals with MGUS and MM, compared to normal bone marrow plasma cells. IGFBP7 gene expression in MM cells is regulated by methylation, shown by pyrosequencing and exposure to demethylating agents (5-aza-2-deoxycytidine). High expression of IGFBP7 in MM cells is associated with adverse survival in two independent cohorts of 247 and 701 newly-diagnosed MM patients treated with high-dose therapy and autologous stem cell transplantation. IGFBP7 is associated with prognostically adverse chromosomal aberrations (t(4;14) and gain of 1q21), MMSET expression, and higher myeloma cell proliferation. In vitro, IGFBP7 overcomes activin A induced osteoblast suppression and promotes osteogenesis. MM cells downregulate IGFBP7 in stromal cells, possibly contributing to the osteoblast suppression found in MM. Conversely, higher IGFBP7 expression is associated with a lower probability of myeloma bone disease.
\end{abstract}

Conclusions: Our data indicate that IGFBP7 expression is a marker for a specific methylation pattern in myeloma, linked to translocation $\mathrm{t}(4 ; 14)$ associated MMSET expression, showing clinical features of adverse prognosis with absence of myeloma bone disease.

Keywords: Multiple myeloma, IGFBP7, Microenvironment, Myeloma bone disease, Survival

\footnotetext{
* Correspondence: niklas.zojer@wienkav.at

${ }^{1}$ Wilhelminen Cancer Research Institute, Department of Internal Medicine I,

Wilhelminenspital, Montleartstraße 37, 1160 Vienna, Austria

Full list of author information is available at the end of the article
} 


\section{Background}

Multiple myeloma (MM) is characterized by the accumulation of malignant plasma cells (PCs) in the bone marrow (BM) [1]. MM cells reside in the BM microenvironment similar to their normal counterparts where they receive essential survival and growth signals from the surrounding stromal compartments [2]. Direct interactions between myeloma cells and bone marrow stromal cells (BMSCs) or osteoclasts [3] as well as the crosstalk through various soluble factors play a major role in the pathophysiology of MM leading to clinical features such as myeloma bone disease, anaemia and immunosuppression [1].

MM cells are closely connected with BMSCs, modify their function and induce the production of tumour promoting factors [4]. Within the growth signalling network of the myeloma microenvironment, IL-6, IGF-1 and insulin play a prominent role [5-7]. An imbalance of the RANKL to OPG ratio promotes osteoclast activation [8] while the secretion of osteoblast inhibitory molecules such as DKK-1 and activin A impairs osteogenesis, leading to myeloma induced bone disease $[9,10]$.

Bone morphogenetic proteins (BMPs) in turn stimulate bone formation [11] and are at the same time potent inhibitors of MM cell survival $[12,13]$. Higher BMP expression in malignant plasma cells is associated with superior overall survival [13]. Less is known, however, about the role of BMP antagonists in MM. In solid malignancies, upregulation of BMP antagonists such as gremlin was shown to promote the growth and survival of tumour cells [14]. We therefore speculated that deregulation of BMP antagonistic proteins in the myeloma microenvironment might be involved in the pathophysiology of MM. To address this question, we analysed the BMP antagonist expression profile in myeloma, identifying insulin like growth factor binding protein 7 (IGFBP7) as a potential gene of interest. IGFBP7 is a secreted protein with IGF-1, insulin [15], VEGFA [16] and activin A [17] binding properties and has been described as BMP antagonist [18]. Methylation dependent silencing of IGFBP7 was reported as associated with unfavourable outcome in lung-, breast-, and pancreatic cancer, as well as hepatocellular carcinoma [19-23]. On the contrary, high IGFBP7 expression was linked to poor prognosis in oesophageal adenocarcinoma as well as head and neck squamous cell carcinomas [24,25]. Recent studies also suggested a role for IGFBP7 in haematological malignancies. In acute lymphoblastic leukemia (ALL) IGFBP7 expression was associated with adverse outcome and shown to interfere with leukemia cell proliferation $[26,27]$. IGFBP7 was also reported to be involved in the crosstalk between BMSCs and ALL cells, mediating asparaginase-resistance in B-lineage ALL cells [27]. Based on these results we were interested in the prognostic and pathophysiologic role of IGFBP7 in MM.

\section{Results}

IGFBP7 gene expression is downregulated in myeloma cells IGFBP7 gene expression levels were significantly decreased in a series (HM group) of CD138 sorted plasma cells from MGUS $(n=22)$ and MM patient samples $(\mathrm{n}=332)$ as well as in human myeloma cell lines (HMCLs) $(\mathrm{n}=32)$ compared to normal plasma cells $(\mathrm{n}=10) \quad(P<0.02)$ whereas IGFBP7 expression was absent in memory B cells (MBCs) and proliferating polyclonal plasmablastic cells (PPCs) (Figure 1A). IGFBP7 gene expression was detectable in $100 \%$ of purified bone marrow plasma cells from healthy individuals, compared to $45.5 \%$ of samples from MGUS patients, $47.7 \%$ from MM patients, $47.1 \%$ of HMCLs and $0 \%$ of MBCs and PPCs, respectively. Expression levels varied widely in bone marrow plasma cell samples from myeloma patients as well as in HMCLs, the latter confirmed by PCR analysis (Figure 1B) and flow cytometry (Figure 1C). Other factors related to BMP antagonism dysregulated in $\mathrm{MM}$ are listed in Additional file 1: Table S1 and Additional file 2: Table S2.

\section{IGFBP7 gene expression is regulated via methylation}

Exposure of HMCLs to the demethylating agent 5-aza-2' deoxycytidine (aza) and/or the histone deacetylase inhibitor Trichostatin A (TSA) showed significant upregulation of IGFBP7 mRNA levels in 4 of 6 cell lines tested (median upregulation with aza + TSA: 3.05 ; range: 1.83 - 21.47; $P<0.05$ ) (Figure 2A). In addition, in KMS-12-BM, IGFBP7 expression changed from not detectable by qPCR in the DMSO control to detectable with aza treatment (not shown). To validate these results, we analysed the promoter methylation status of IGFBP7 in a "low" (KMS12-BM) and "high" (OPM-2) expressing MM cell line as well as in CD138 purified cells of four myeloma patients. Pyrosequencing demonstrated methylation of the IGFBP7 promoter region generally in accordance with the IGFBP7 gene expression levels by qPCR (Figure 2B). The methylation status of one patient, however, was not in line with the qPCR results, showing no methylation in the analysed promoter region despite suppressed IGFBP7 expression. This suggests that methylation of other regulatory regions or other mechanisms might mediate downregulation of IGFBP7 gene expression in certain MM cases.

\section{IGFBP7 gene expression in MM cells of patients is linked to adverse survival and poor risk cytogenetics}

IGFBP7 gene expression in MM cells was significantly associated with event free survival (EFS) and overall survival (OS) in both patient cohorts analysed. Patients with high IGFBP7 expression levels had a significantly worse outcome compared to those with low IGFBP7 expression in the HM (median EFS: 34.2 vs. 22.6 months, $P<0.001$; median OS: NA vs. 59.1 months, $P=0.006$ ) and the LR 
A

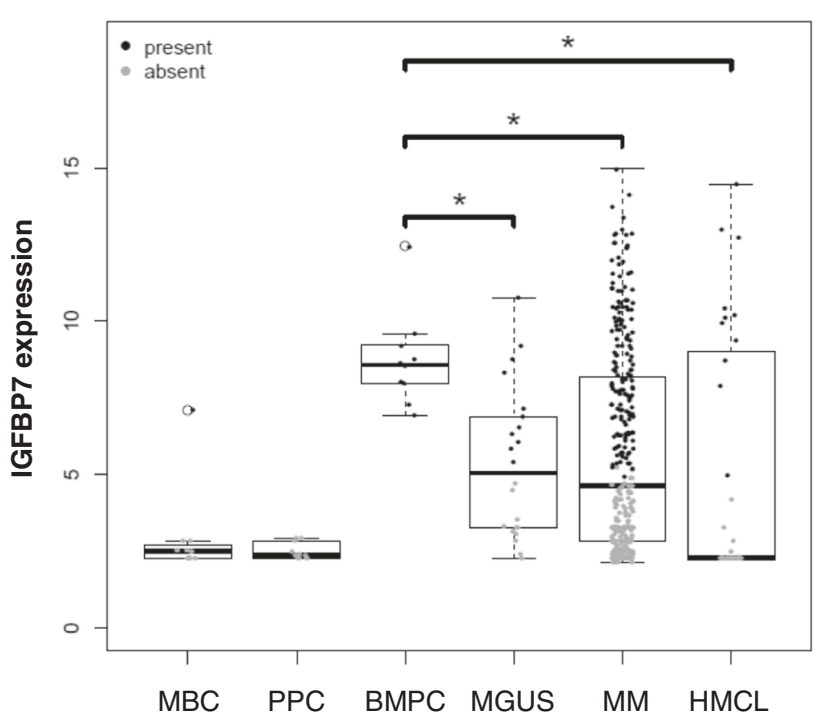

B

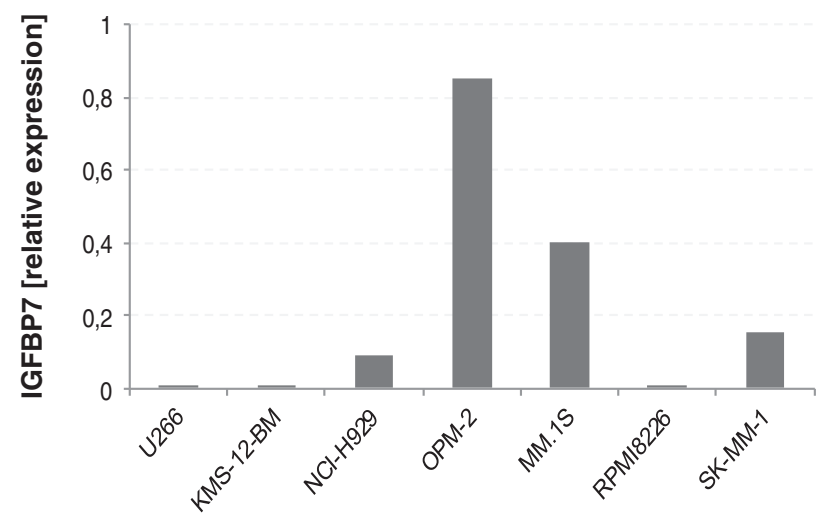

C

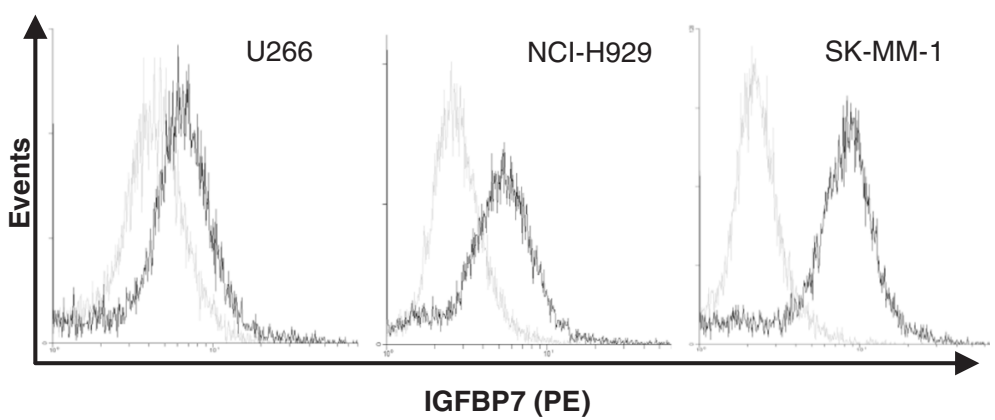

Figure 1 Insulin like growth factor binding protein 7 (IGFBP7) is downregulated in multiple myeloma. (A) IGFBP7 expression levels were analysed by gene expression profiling of memory B cells (MBC), polyclonal plasmablastic cells (PPC) as well as of CD138+ purified cells from healthy donors (BMPC), newly diagnosed myeloma patients (MM), patients suffering from monoclonal gammopathy of undetermined significance (MGUS) and human MM cell lines (HMCLs). Grey data points indicate an absent, black data points a present Affymetrix detection call. The asterisk indicates statistical significance ( ${ }^{*} P<0.02$ ). IGFBP7 expression analysis by qPCR (B) and flow cytometry (C) confirmed heterogeneous expression levels in myeloma cell lines. (B) Expression levels by qPCR are displayed relative to peripheral blood mononuclear cells (PBMCs) of healthy donors $(n=3)$. IGFBP7 expression in PBMCs was arbitrarily set at 1. (C) Intracellular staining of MM cells for IGFBP7 protein levels confirmed the variable expression of IGFBP7 transcripts observed by qPCR. MM cells were stained with either anti-IGFBP7 antibody (black lines) or control antibody (light grey lines), followed by PE-conjugated anti-goat antibody. 




group (median EFS: 76.4 vs. 42.5 months, $P<0.001$; median OS: NA vs. 63.3 months, $P<0.001$ ) (Figure 3). As optimal cut-offs for IGFBP7 expression were different between the cohorts (see methods section), we applied the same fraction of patients defined as "high" IGFBP7 expressers in the HM-cohort $(46 / 274,18.6 \%)$ to the LR- cohort (131/701, 18.6\%), confirming the association with EFS and OS (Additional file 3: Figure S1).

High expression of IGFBP7 was likewise associated with poor risk cytogenetics, most notably translocation $\mathrm{t}(4 ; 14)(P<0.0001)$ and gain of $1 \mathrm{q} 21(P=0.039)$. No significant correlation was observed with the translocation 


\section{HM group}

A

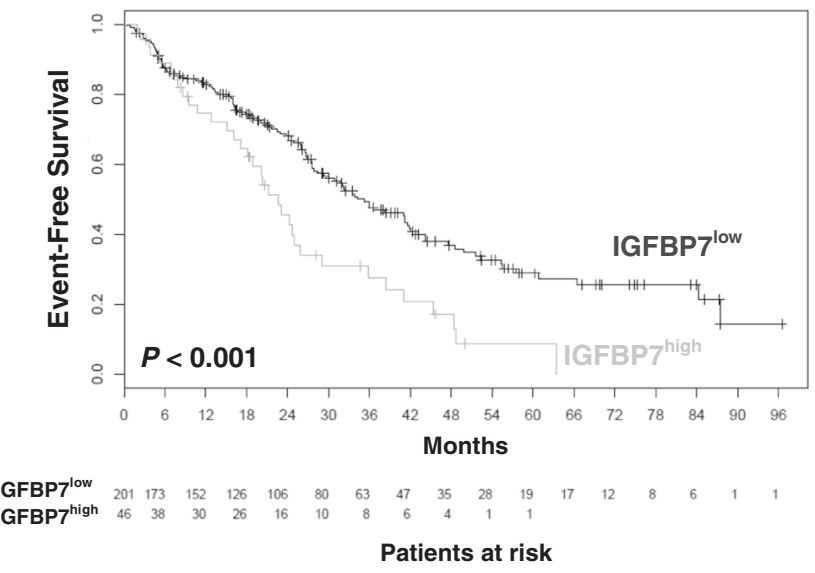

B

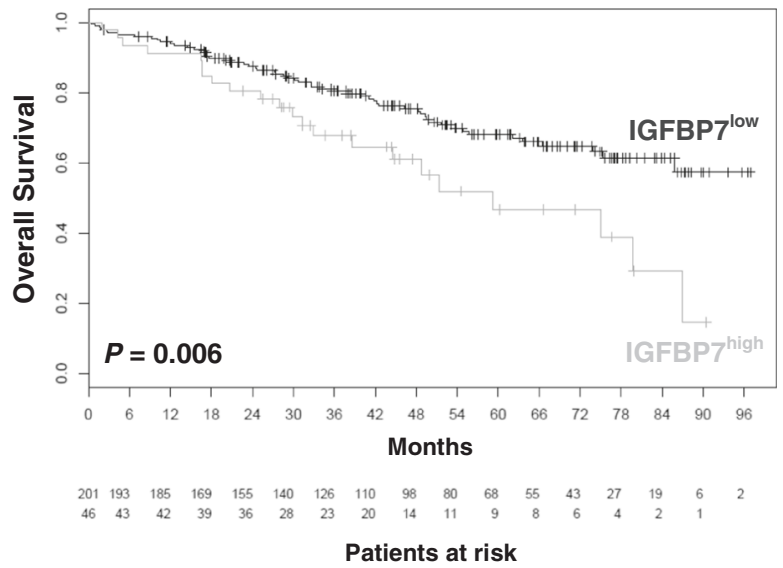

\section{LR group}

C

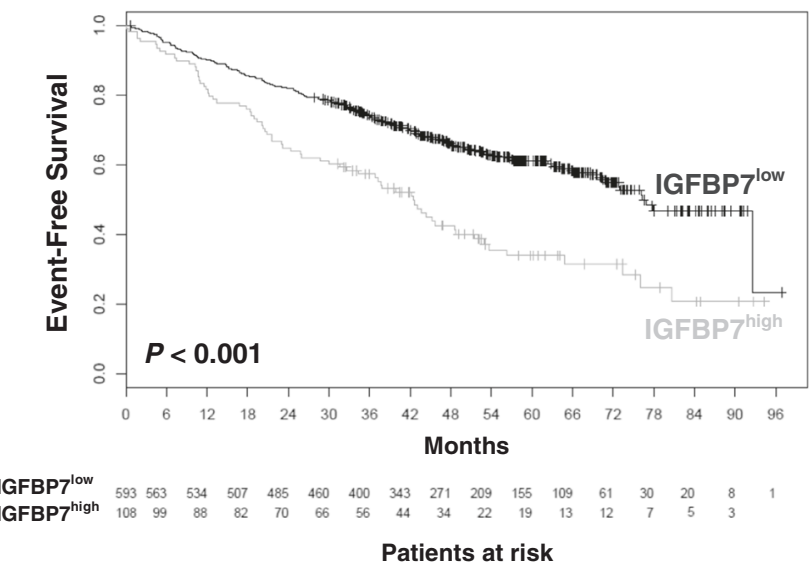

D

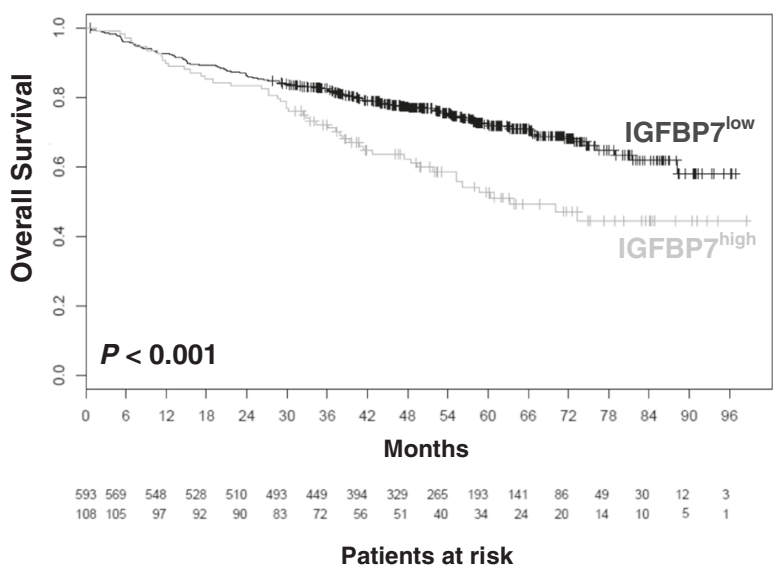

Figure 3 High IGFBP7 expression is predictive for poor outcome. IGFBP7 expression was analysed in CD138+ purified MM cells of newly diagnosed, previously untreated myeloma patients of the Heidelberg-Montpellier group ( $\mathrm{HM} ; n=247)$, as well as for validation purposes in the independent Little-Rock ( $(L R ; n=701)$ patient cohort as depicted in the Methods section. In both patient series, high IGFBP7 expression was associated with worse event-free (A, C) and overall survival (B, D).

$\mathrm{t}(11 ; 14)$ and deletion 17p (Additional file 4: Figure S2). The association between IGFBP7 expression levels and $\mathrm{t}(4 ; 14)$ was further validated by an in-silico analysis of two additional publically available GEP-datasets $[28,29]$. In both, IGFBP7 expression was significantly higher in the GEP-defined MMSET ${ }^{\text {high }}$ expressing (typically $\mathrm{t}(4 ; 14)$ positive) patients compared to the other molecular subgroups (Additional file 5: Figure S3).

High IGFBP7 expression levels were also associated with the GEP-based proliferation index (GPI) for the HM $(R=0.21, P=0.008)$ and LR group $(R=0.22, P=$ $0.037)$, which in turn is associated with adverse survival. IGFBP7 expression was not associated with tumour mass surrogates such as ISS stage or beta 2 microglobulin (B2M) levels.

IGFBP7 impacts on myeloma cell proliferation and viability Exposure to recombinant human IGFBP7 (rhIGFBP7) weakly but significantly reduced viable cell numbers in 6 of 7 HMCLs in a dose dependent manner (relative viability compared to control: $0.68 \pm 0.05-0.91 \pm 0.02$, $P<0.05)$. In RPMI8226, treatment with rhIGFBP7 at $10 \mu \mathrm{g} / \mathrm{ml}$ similarly led to a minor reduction of viable cell numbers by $7.8 \pm 4.9 \%$ compared to control, although not statistically significant $(P=0.05)$ (Figure $4 \mathrm{~A})$. In line with this, treatment with rhIGFBP7 slightly reduced viability 

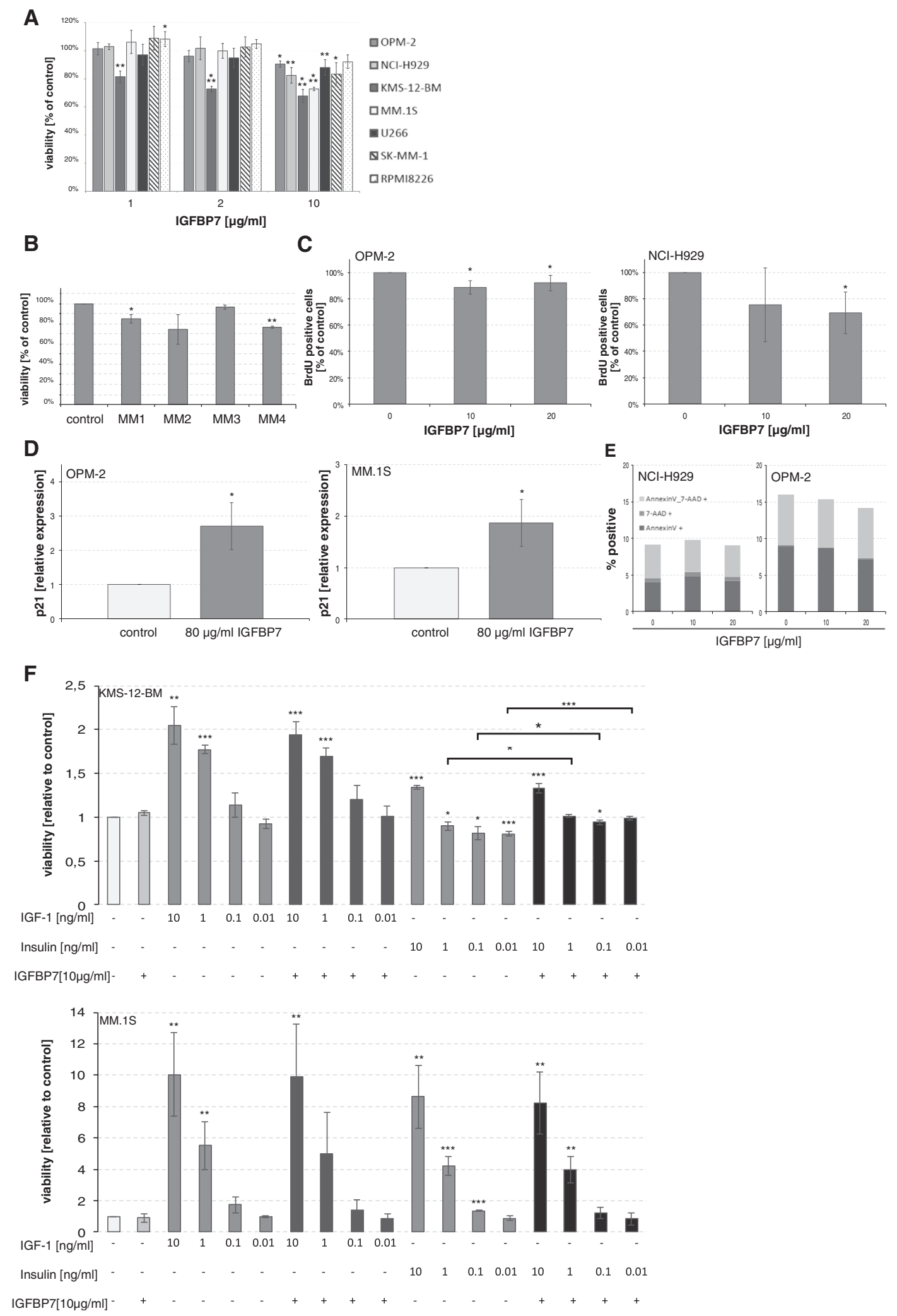

Figure 4 (See legend on next page.) 
(See figure on previous page.)

Figure 4 IGFBP7 inhibits myeloma cell proliferation. MM cell lines (A) and primary MM cells (B) were treated with PBS/BSA 0.1\% or recombinant human IGFBP7 (rhIGFBP7) at the indicated concentrations for 96 hours. Primary cells were treated with IGFBP7 at $10 \mu \mathrm{g} / \mathrm{ml}$. Viable cell numbers were evaluated as outlined in the methods section. (C) Proliferation of MM cells was assessed by BrdU assay. HMCLs were treated for 72 hours with PBS/BSA $0.1 \%$ or rhIGFBP7 at the indicated concentrations. BrdU was added for the last 19 hours of incubation. Proliferation was assessed by measuring absorbance at $450 \mathrm{~nm}$. (D) Expression of p21 was analysed by quantitative PCR after 24 hour treatment with PBS/BSA $0.1 \%$ or rhIGFBP7 at $80 \mu \mathrm{g} / \mathrm{ml}$. (E) Apoptosis of HMCLs was determined by Annexin $V$ and 7-AAD staining after a 72 hour incubation period in the presence of PBS/BSA $0.1 \%$ or rhlGFBP7 at the indicated concentrations. Graphs represent the mean (\% positive cells on FACS) of three independent experiments performed in duplicates. (F) KMS-12-BM and MM.1S were cultured in Syn-H serum free medium in the presence of rhIGFBP7, IGF-1 and/or insulin at the indicated concentrations for 96 hours before viable cell numbers were determined. (A-D, F) Values represent the mean \pm SD of three independent experiments performed in triplicates and mean \pm SD of triplicate experiments for primary MM cells. Asterisks indicate statistical significance compared with the control $\left(* P<0.05,{ }^{* *} P<0.01,{ }^{* * *} P<0.001\right)$.

in 4 of 4 primary MM cell samples tested, reaching statistical significance in 2 of 4 samples (Figure 4B). Analysis of proliferation by BrdU assay mirrored the viability assessment, showing weakly reduced proliferation of MM cells exposed to IGFBP7 (BrdU positive cells relative to control: $0.92 \pm 0.04$ and $0.69 \pm 0.16$ with $20 \mu \mathrm{g} / \mathrm{ml} \mathrm{rhIGFBP7}$ in OPM-2 and NCI-H929, respectively; $P<0.05$ ) (Figure 4C). Analysis of cell cycle inhibitory proteins after short-term treatment with rhIGFBP7 showed a significant upregulation of p21 in OPM-2 and MM.1S (relative induction $2.7 \pm 0.68$ and $1.9 \pm 0.45$ compared to control, respectively; $P<0.05$ ) (Figure 4D), while no significant changes were observed in the expression levels of p16 and p27 (data not shown). In contrast, no induction of apoptosis in MM cells could be observed related to IGFBP7 exposure (Figure 4E).

As IGFBP7 harbors binding sites for IGF-1 and insulin we also examined whether IGFBP7 alters the stimulatory activity of these growth factors. IGF-1 and insulin at $0.01-10 \mathrm{ng} / \mathrm{ml}$ potently stimulated the survival in 2 of 4 MM cell lines in Syn-H serum free medium (IGF-1 $10 \mathrm{ng} / \mathrm{ml}: 2.1 \pm 0.2$ and $10.0 \pm 2.7$ fold viable cells compared to control in KMS-12-BM and MM.1S, respectively; insulin $10 \mathrm{ng} / \mathrm{ml}: 1.3 \pm 0.02$ and $8.6 \pm 2.0$ ), which was not abrogated by combined treatment with $10 \mu \mathrm{g} / \mathrm{ml}$ rhIGFBP7 (Figure 4F).

\section{MM cells induce downregulation of IGFBP7 in BMSCs}

We next characterized the expression of IGFBP7 in $\mathrm{BM}$ stromal cells. IGFBP7 expression was 31 times higher in BMSC TERT+ and 11 fold higher in primary (normal) BMSCs compared to peripheral blood mononuclear cells. In comparison with OMP-2, the highest expressing MM cell line in our analysis, IGFBP7 expression was 37 fold higher in BMSC TERT+ cells and 13 fold higher in primary BMSCs.

Co-cultures of BMSC TERT+ cells and HMCLs showed a significant downregulation of IGFBP7 in BMSCs in the presence of 4 of 5 HMCLs in a contact dependent manner (relative expression compared to control: 0.06 - 0.50; $P<0.05)$ (Figure 5A). Similar results were obtained using primary MM cell samples $(P<0.001)$ (Figure $5 \mathrm{~B})$. Thus,
MM cells have the capacity to significantly downregulate the expression of IGFBP7 in BM stromal cells, which highly express IGFBP7 in monoculture. When IGFBP7 expression levels in whole BM samples of myeloma patients were compared with those of healthy donors, significantly lower levels in the MM samples were likewise found $(P=0.012)$ (Figure $5 C)$.

\section{IGFBP7 promotes osteoblast development and might protect from myeloma bone disease}

As BMSCs have multilineage potential and can differentiate into osteoblasts, we were interested in the role of IGFBP7 in osteoblast development. IGFBP7 gene expression increased during the course of differentiation of primary (ND) BMSCs (Figure 6A) and treatment with rhIGFBP7 further stimulated osteoblast formation, indicated by a dose dependent increase in alkaline phosphatase activity at day 7 (1.42 \pm 0.29 fold increase compared to control; $P<0.05)$ and $14(1.81 \pm 0.18$ fold increase compared to control, $P<0.001$ ) of osteogenesis (Figure 6B). Interestingly, we also observed a significant reduction in Dickkopf-1 expression with rhIGFBP7 treatment during osteogenesis $(0.22 \pm 0.06$ fold decrease compared to control; $P<0.05)$ but no change in other $\mathrm{OB}$ marker genes such as Runx2, Col1A and Dlx5 (data not shown).

As IGFBP7 was shown to bind activin A [17] we studied whether rhIGFBP7 treatment could overcome the inhibitory action of activin A on osteogenesis. As expected, activin A demonstrated osteoblast inhibitory properties reflected by a dose dependent decrease of alkaline phosphatase activity. Importantly, treatment with rhIGFBP7 was able to partially reverse this effect in primary and immortalized BMSCs (Figure 6C-D). In our patient series we observed significantly lower expression levels of IGFBP7 in MM cells of patients with advanced bone disease compared to patients with no osteolytic lesions (Figure 6E).

\section{Discussion}

Various soluble factors have been identified in the signaling crosstalk between myeloma and stromal cells including IGF-1, IL6, DKK-1, RANKL and activin A [1,2,5-10]. In this study we identified IGFBP7, a 


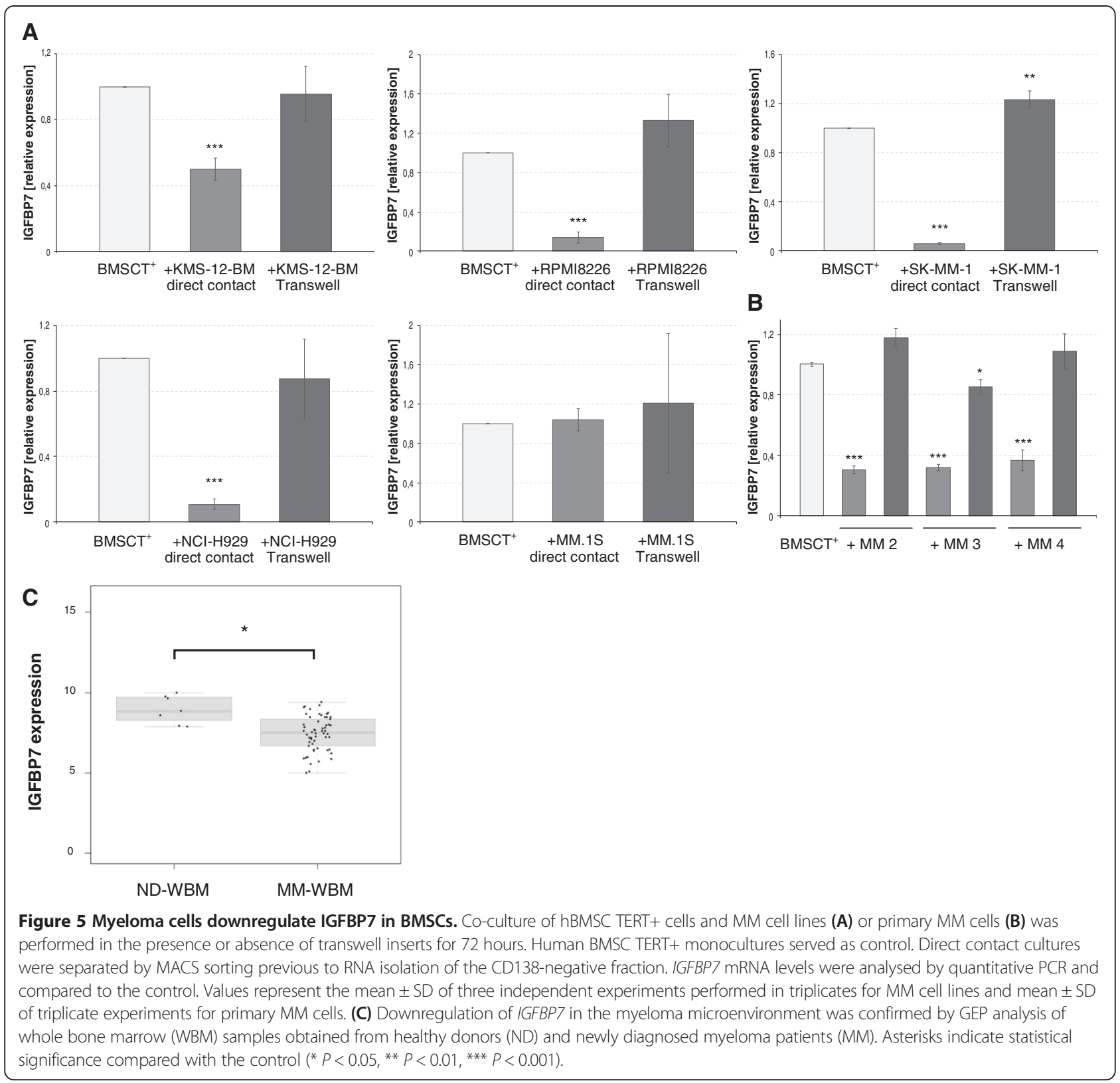

secreted factor with BMP antagonistic activity [18], and binding sites for IGF-1, insulin [15], VEGFA [16] and activin A [17] as a potential novel player in the pathogenesis of MM, including myeloma bone disease. BMPs are known to induce apoptosis in MM cells [12,13], so upregulation of BMP antagonists might be envisaged to be used as a protective mechanism by myeloma cells. Median IGFBP7 expression levels, although IGFBP7 displayed a heterogenous expression profile, were found to be downregulated in malignant plasma cells compared to their normal counterparts, suggesting that myeloma cells do not rely on the BMP antagonistic activity of IGFBP7.
We show that IGFBP7 downregulation in MM cells can be explained by promoter methylation. Such a downregulation of IGFBP7 by promoter methylation was previously observed in solid tumours including melanoma, prostate, lung and breast cancer as well as T-ALL, suggesting a common mechanism in cancer [19,21,30-32]. Plasma cells from MGUS patients already display reduced IGFBP7 expression, indicating that deregulation of IGFBP7 might occur early in the course of the disease.

IGFBP7 belongs to the family of insulin like growth factor binding proteins (IGFBPs) consisting of six highand several low-affinity members [33]. IGFBPs were 
A

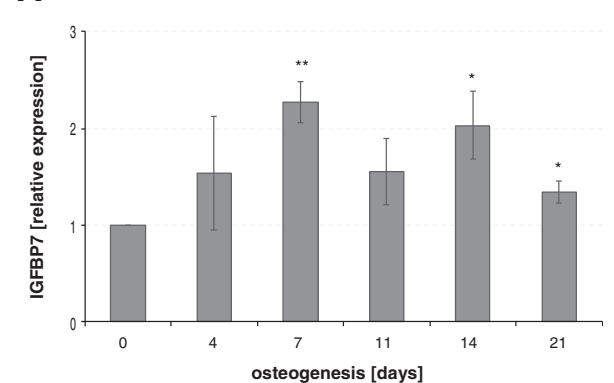

\section{C}

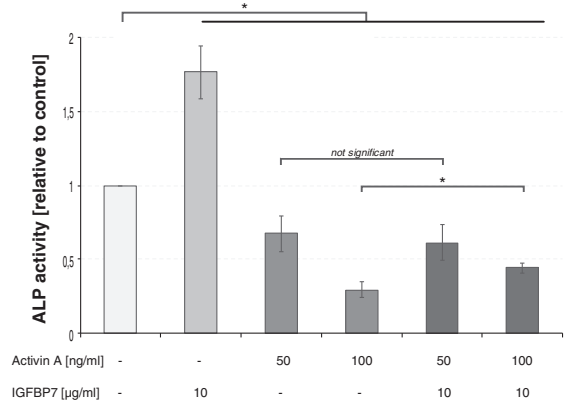

B

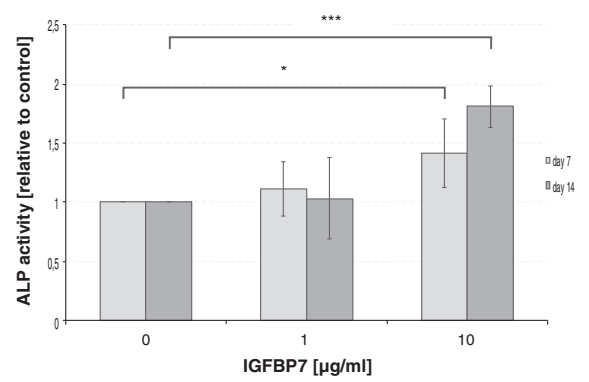

D

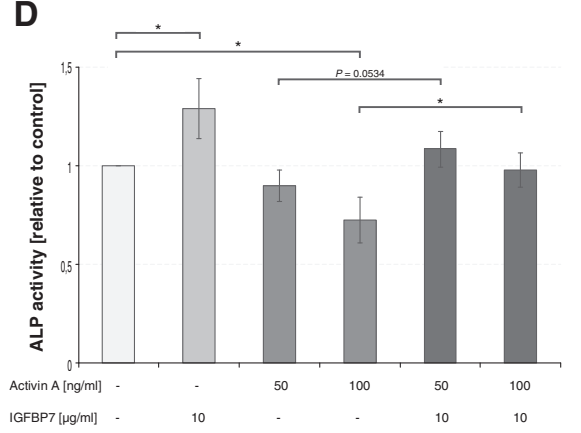

E

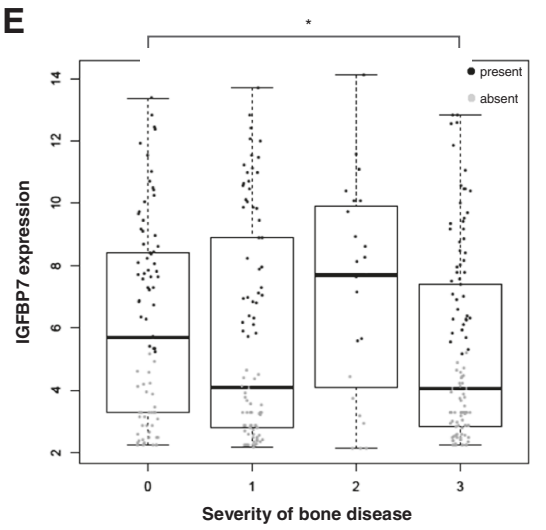

Figure 6 IGFBP7 promotes osteogenesis and is associated with myeloma bone disease. (A) Primary BMSCs were cultured in osteogenic medium for 21 days. IGFBP7 expression was analysed during osteogenesis by quantitative PCR at the indicated time points. The graph represents the relative expression compared to day 0 of osteogenesis. (B) Alkaline phosphatase activity in primary BMSCs was determined at days 7 and 14 of differentiation in the presence or absence of rhlGFBP7 (1 or $10 \mu \mathrm{g} / \mathrm{ml}$ ) and is displayed relative to the control (PBS/BSA 0.1\%). For neutralization experiments, alkaline phosphatase activity in primary human BMSCS (C) and BMSC TERT ${ }^{+}$cells (D) was analysed at day 14 of osteogenesis in the presence of activin A (50 or $100 \mathrm{ng} / \mathrm{ml}$ ) and/or rhlGFBP7 (10 $\mu \mathrm{g} / \mathrm{ml})$. Results are displayed relative to the control (PBS/BSA 0.1\%). (A-D) Values represent the mean \pm SD of three independent experiments performed in triplicates. (E) IGFBP7 expression was analysed with regard to the severity of myeloma bone disease. Grey data points indicate an absent, black data points a present Affymetrix detection call. Asterisks indicate statistical significance compared with the control $\left.{ }^{*} P<0.05,{ }^{* *} P<0.01,{ }^{* * *} P<0.001\right)$.

described to act via IGF dependent and independent mechanisms [33]. Contrary to other family members, in particular IGFBP3, IGFBP7 possesses low binding affinity for IGFs [15,34]. Accordingly, unlike IGFBP3 [6], IGFBP7 was not able to antagonize the growth stimulatory activity of IGF-1 and insulin on MM cell lines.

Previous studies indicated a role for IGFBP7 as tumour suppressor in several solid malignancies including melanoma, hepatocellular carcinoma, thyroid, breast, bladder and colon cancer by either direct induction of apoptosis and/or inhibition of tumour growth by deregulation of p16, p21, p53 and ERK signaling [19,26,35-38]. However, results regarding the role of IGFBP7 in solid tumours are inconsistent and recent studies provide a more complex picture of IGFBP7 in different entities. In glioblastoma, IGFBP7 was shown to stimulate tumour cell proliferation and angiogenesis of brain endothelial cells $[39,40]$. Similarly, elevated IGFBP7 expression was detected in specific stages of colorectal cancer and silencing of IGFBP7 reduced proliferation as well as colony 
formation in colorectal cancer cell lines [41]. Expression of IGFBP7 was also detected in cancer-associated fibroblasts, endothelial cells, mesenchymal tumours and malignant epithelial cells with a mesenchymal phenotype. In the latter, loss of IGFBP7 significantly impaired the anchorage independent growth of tumour cells. Furthermore, IGFBP7 expression in cancer stromal cells supported the growth of colon cancer cells [41]. These findings establish a complex variety of functions for IGFBP7 depending on the malignancy investigated.

In haematological malignancies, IGFBP7 was found to be associated with BAALC expression in T-ALL and to correlate with poor survival [26]. Similarly, in B-cell ALL IGFBP7 expression in BMSCs was found to be associated with asparaginase resistance and decreased leukemia-free survival [27]. In our study, high expression levels of IGFBP7 predicted poor outcome in two large and independent cohorts of MM patients. Whereas the mean values and standard deviations $(5.564 \pm 3.213$ vs. $3.155 \pm$ 1.966) as well as the percentage of patients expressing IGFBP7 as defined by the PANP algorithm (marginal and present, 44.9 vs. $12.9 \%$ ) significantly differed between the HM- and LR-cohort, the prognostic impact of IGFBP7 expression was comparable between both cohorts. Observed differences in frequency and height of expression are most likely due to different amplification protocols used (double vs. single amplification) [42-44].

IGFBP7 expression in MM cells was linked to prognostically adverse chromosomal aberrations such as translocation $\mathrm{t}(4 ; 14)$ and amplification 1q21. The multiple myeloma SET domain (MMSET) protein, specifically overexpressed in $t(4 ; 14)$ myeloma, is a histone methyl transferase shown to modulate DNA methylation, thereby inducing the activation of specific target genes [45]. Interestingly, IGFBP7 expression was found to be regulated by MMSET in myeloma cells [45] which is in line with our observation of higher IGFBP7 transcript levels in $\mathrm{t}(4 ; 14)$ cases. The association between MMSET expression and expression of IGFBP7 was confirmed by in-silico analysis of two open-source GEP datasets. This suggests that IGFBP7 represents a novel marker of high-risk myeloma, defined by an epigenetic signature and regulated by MMSET.

The growth attenuating effects of IGFBP7 we observed in vitro were rather small and evident only at high IGFBP7 concentrations [46]. Moreover, we show that, in clinical myeloma samples, IGFBP7 expression is associated with higher myeloma cell proliferation, in turn associated with adverse prognosis. The phenotype of MMSET expressing myeloma seems to overrule the weak inhibitory activity of IGFBP7 on myeloma cell proliferation. Thus, rather than being mechanistically involved in the poor outcome, IGFBP7 might rather be seen as a marker associated with a high-risk disease phenotype.
We show upregulation of IGFBP7 in BMSCs while undergoing osteogenic differentiation and treatment with exogenous rhIGFBP7 further stimulating osteoblast activity. IGFBP7 treatment led to a significant downregulation of DKK1, a major osteoblast inhibitory molecule in MM [9]. Furthermore, we were able to show that IGFBP7 can neutralize the inhibitory effects of activin A on osteoblast development. Activin A mediated inhibition of osteogenesis leads to uncoupling of the delicate balance between bone formation and degradation thus contributing to myeloma related bone destruction [10,47]. Our results suggest that the downregulation of IGFBP7 in the myeloma microenvironment enables activin A to release its full destructive potential.

Possibly, the lack of IGFBP7 in the microenvironment is aggravated by low or absent intrinsic expression of IGFBP7 in myeloma cells. In contrast, in myeloma cases with high IGFBP7 expression the downregulation of this molecule in the microenvironment might be counterbalanced by production in myeloma cells, possibly explaining the correlation of higher intrinsic IGFBP7 expression and absence of advanced bone disease. In line with this, prior studies reported osteolytic lesions to occur less frequently in myeloma cases harboring a translocation $\mathrm{t}(4 ; 14)[48]$.

\section{Conclusions}

Taken together, our results suggest that IGFBP7 might play a dual role in the pathophysiology of MM. Maintained expression of IGFBP7 in myeloma cells represents a novel prognostic marker linked to prognostically adverse chromosomal aberrations and a specific epigenetic profile. In stromal cells in the vicinity of MM cells IGFBP7 expression is suppressed, releasing the full potential of osteoblast inhibitory molecules like activin A, which then promote myeloma bone disease. In addition, these findings might provide a mechanistic link for the reduced frequency of osteolytic lesions in $t(4 ; 14)$ associated high-risk myeloma.

\section{Methods}

\section{Patients}

Patients presenting with previously untreated MM ( $\mathrm{n}=$ 332) or monoclonal gammopathy of unknown significance (MGUS; $\mathrm{n}=22$ ) at the University Hospitals of Heidelberg and Montpellier (HM group) as well as 10 healthy normal donors have been included in the study approved by the Heidelberg ethics committee (\#229/ 2003 and S-152/2010) after written informed consent was obtained in accordance with the Declaration of Helsinki. Patients were diagnosed, staged and response to treatment assessed according to standard criteria. Normal bone marrow plasma cells and myeloma cells were purified as previously published [13,44]. Memory 
B cells (MBCs; $\mathrm{n}=11)$ and polyclonal plasmablasts (PPCs; $\mathrm{n}=10$ ) were obtained as reported [49]. Aliquots of unpurified whole bone marrow from myeloma patients $(\mathrm{n}=154)$ and healthy donors were obtained after $\mathrm{NH}_{4}$ lysis.

Bone disease was assessed by conventional X-ray and whole body $\mathrm{CT}$ scan and graded as 0 (normal bone structure), 1 (osteopenia/osteoporosis), 2 (1-3 osteolyses) or 3 (major structural damage, $>3$ osteolyses) as described previously [44].

The prognostic impact of IGFBP7 expression data was validated on an independent cohort of 701 newly diagnosed, therapy-requiring patients treated within the total therapy 2 or 3 protocol, respectively (LR group), for whom gene expression data are publicly available (see below) [50,51]. All patients in both cohorts, i.e. the HMand the LR-group, received high-dose chemotherapy followed by autologous stem cell transplantation.

\section{Cells and culture conditions}

Human multiple myeloma cell lines (HMCLs) U266, KMS12-BM, OPM-2, NCI-H929, SK-MM-1 and RPMI8226 were obtained from the German Collection of Microorganisms and Cell Cultures (Braunschweig, Germany). MM.1S cells were kindly provided by Dr Steven Rosen (Northwestern University, Chicago, IL). All HMCLs were cultivated in RPMI-1640 medium supplemented with $10 \%$ heatinactivated fetal bovine serum, $2 \mathrm{mM} \mathrm{L}$-glutamine and $100 \mathrm{U} / \mathrm{ml}$ penicillin/streptomycin (Gibco).

A human bone marrow mesenchymal stromal cell line immortalized by enforced expression of telomerase (hBMSC TERT+) was kindly provided by Dr Dario Campana (St. Jude Children's Research Hospital, Memphis, $\mathrm{TN}$ ) and cultured in RPMI-1640 medium supplemented with 10\% FBS, $2 \mathrm{mM}$ L-glutamine, $100 \mathrm{U} / \mathrm{ml}$ penicillin/ streptomycin and $1 \mu \mathrm{M}$ hydrocortisone (Sigma-Aldrich). Primary human BMSCs (Lonza) were cultured in $\alpha$-MEM (Gibco) supplemented with 10\% FBS, $2 \mathrm{mM} \mathrm{L-Glutamine,}$ $100 \mathrm{U} / \mathrm{ml}$ penicillin/streptomycin and $1 \mathrm{ng} / \mathrm{ml}$ FGF-2 (Peprotech).

For co-culture experiments, $0.25 \times 10^{6} \mathrm{TERT}^{+}$hBMSCs were seeded in 6-well plates and cultured over night before $0.5 \times 10^{6} \mathrm{MM}$ cells were added per well for 72 hours in the presence or absence of transwell inserts $(0.4 \mu \mathrm{m}$ pore size; BD). Direct contact cultures were MACS sorted by CD138 selection previous to RNA isolation of the CD138-negative population. Purity of the negative sort was $\geq 90 \%$ by cytological assessment.

\section{Cytotoxicity assay}

Cell Counting Kit-8 (Sigma) was used to analyze the impact of recombinant human IGFBP7 (rhIGFBP7; Peprotech) on myeloma cell growth following the manufacturer's directions. In brief, $2 \times 10^{4}$ cells per well were seeded in flat-bottomed 96-well plates (Iwaki) in the presence of rhIGFBP7 $(0-10 \mu \mathrm{g} / \mathrm{ml})$. Neutralization experiments with recombinant human IGF-1 (10 or $100 \mathrm{ng} / \mathrm{ml}$ ) (R\&D Systems), insulin (10 or $100 \mathrm{ng} / \mathrm{ml}$ ) (Roche Diagnostics) and IGFBP7 (1 or $10 \mu \mathrm{g} / \mathrm{ml}$ ) were performed in serum free Syn-H medium (ABCell-Bio) according to Sprynski et al. [6]

\section{BrdU assay}

Proliferation of myeloma cells was assessed by BrdU assay (Calbiochem) following the manual. BrdU label was added for the last 19 hours of the culture period. Proliferation was determined by absorbance measurement at $450 \mathrm{~nm}$ using a HTS 7000 Bio Assay Reader (Perkin Elmer).

\section{Flow cytometry}

Intracellular staining of IGFBP7 was performed using the BD Cytofix/Cytoperm ${ }^{\text {Tux }}$ Plus Kit (BD Biosciences) according to the manual. After fixation and permeabilization, cells were incubated with the primary goat-anti-human IGFBP7 antibody (sc-6064; Santa Cruz Biotechnology Inc., Santa Cruz, CA, USA) or the corresponding isotype control (sc-3887; Santa Cruz) for $30 \mathrm{~min}$ at $4^{\circ} \mathrm{C}$. Thereafter cells were washed and incubated for $30 \mathrm{~min}$ at $4^{\circ} \mathrm{C}$ with a secondary PE-conjugated donkey-anti-goat antibody (sc-3857; Santa Cruz). Analysis was performed on a FACScan (BD Biosciences).

Induction of apoptosis was determined by FACS analysis of Annexin V/7-AAD stainings (BD Biosciences). HMCLs were seeded at a concentration of $2.5 \times 10^{5} / \mathrm{ml}$ and treated with either PBS/BSA $0.1 \%$ (control) or rhIGFBP7 $(10-20 \mu \mathrm{g} / \mathrm{ml})$ for 72 hours. Cells were incubated for 15 min with Annexin V and 7-AAD in the dark before performing analysis.

\section{Quantitative RT-PCR}

Total RNA was isolated using RNeasy kit (Qiagen) and cDNA synthesis was performed with M-MuLV reverse transcriptase (New England Biolabs). IGFBP7, p16, p21, p27, Runx2, Dlx-5, Col1A and DKK-1 expression levels were analysed by quantitative PCR (qPCR) using TaqMan Universal PCR Master Mix and pre-designed TaqMan gene expression assays (Applied Biosystems). RPLPO served as endogenous control. Reactions were carried out in $25 \mu \mathrm{l}$ volumes and run on the ABI Prism 7300 platform (Applied Biosystems). All samples were run at least in duplicates.

\section{Methylation}

For IGFBP7 induction experiments HMCLs were seeded at $2 \times 10^{5} / \mathrm{ml}$ and cultivated in the presence of $0.1 \%$ DMSO (control) or $500 \mathrm{nM}$ 5-aza-2'-deoxcytidine (aza; Sigma) for 96 hours. Trichostatin A (TSA; Sigma) 
was added at a concentration of $50 \mathrm{ng} / \mathrm{ml}$ for the last 24 hours of the culture period.

Analysis of the IGFBP7 promoter methylation status was performed by varionostic GmbH (Ulm, Germany) using pyrosequencing technology.

\section{Osteogenic differentiation}

For osteoblast development, BMSCs were seeded at a density of $12500-25000$ per $\mathrm{cm}^{2}$ and grown to $70-80 \%$ confluence. Osteoblast differentiation was initiated by changing the medium to $\alpha$-MEM supplemented with $15 \%$ FBS, $2 \mathrm{mM}$ L-Glutamine, $100 \mathrm{U} / \mathrm{ml}$ penicillin/ streptomycin, $10 \mathrm{nM}$ dexamethasone (Sigma), $50 \mu \mathrm{g} / \mathrm{ml}$ ascorbic acid (Sigma) and $10 \mathrm{mM} \beta$-glycerophosphate (Sigma). Osteogenic medium was changed every 3-4 days. Recombinant human IGBFP7 (1 or $10 \mu \mathrm{g} / \mathrm{ml})$ and/ or activin A (50 or $100 \mathrm{ng} / \mathrm{ml}$ ) (Peprotech) were added with every medium change. Cells treated with PBS/BSA $0.1 \%$ served as control.

\section{Alkaline phosphatase activity assay}

Alkaline phosphatase activity was determined at day 14 of differentiation using the AttoPhos ${ }^{\bullet}$ AP Fluorescent Substrate System (Promega) following the manual. Fluorescence was measured at $595 \mathrm{~nm}$ with excitation at $430 \mathrm{~nm}$. A standard curve was obtained by diluting the supplied Calibrator solution (500 $\mathrm{ng} \mathrm{BBT} / \mathrm{ml}$ ) in AttoPhos buffer.

\section{Gene expression profiling}

Gene expression profiling was performed as previously published [44] using U133 2.0 plus arrays according to the manufacturer's instructions (Affymetrix, Santa Clara, CA, USA). Expression data are deposited in Array Express under the accession numbers E-MTAB-317 as well as E-TABM-1138 and Gene Expression Omnibus GSE24080 (the latter two for the LR group). When different probe sets were available for the same gene, we chose the probe set yielding the maximal variance and the highest signal.

\section{Interphase fluorescence in situ hybridization}

Analyses were performed on CD138-purified plasma cells as described [52] using probes for the detection of numerical aberration of the chromosomal regions 1q21, $5 \mathrm{p} 15 / 5 \mathrm{q} 35,9 \mathrm{q} 34,13 \mathrm{q} 14.3,15 \mathrm{q} 22,17 \mathrm{p} 13$, as well as the IgH-translocations $\mathrm{t}(11 ; 14)(\mathrm{q} 13 ; \mathrm{q} 32)$, and $\mathrm{t}(4 ; 14)(\mathrm{p} 16.3$; q32) (Kreatech, Amsterdam, The Netherlands and MetaSystems, Altlussheim, Germany).

\section{Statistical analysis}

Correlations (Spearman and Pearson) and survival analysis (Cox regression analysis) were performed using SPSS statistics 17.0. For the analysis of in vitro experiments, two-tailed unpaired $t$ test was performed using Prism 5 (GraphPad Software Inc., La Jolla, CA, USA). $P$-values $<0.05$ were considered to be statistically significant.

Gene expression analyses were performed on GC-RMA preprocessed data sets. To assess presence ("expressed") or absence ("not expressed") of gene expression, the "Presence-Absence calls with Negative Probesets" (PANP) algorithm was used [53]. For the analysis of the prognostic value of IGFBP7, patients with high and low IGFBP7 expression in the HM cohort were delineated using maximally selected rank statistics as implemented in the maxstat $\mathrm{R}$ package (http://cran.r-project.org/ web/packages/maxstat/index.html). The survival function was assessed by means of the Kaplan-Meier method (rms package in R). The log rank test was used to test for statistically significant survival curve differences. An effect was considered as statistically significant if the $P$-value of its corresponding statistical test was not higher than 5\%. All computations were performed using R 3.1.0 (http://www.r-project.org/) and Bioconductor 2.14.

For validation of the impact of IGFBP7 expression on survival, cel-files from 701 patients treated within the total therapy 2 or 3 protocol (LR group), were preprocessed as described above (GC-RMA), and the same analysis strategy followed to obtain an optimal cut-off (maxstat), i.e. the optimal cut-off was derived as the mean of the cut-offs derived for EFS and OS. This separate analysis yielded two different cut-off values for the HM- and LR-cohort. As the generation of two different cut-offs for the HM and LR-group, i.e. delineating different fractions of patients between in the different cohorts, might give an over-optimistic validation, we likewise applied the fraction of patients defined as "high IGFBP7 expressing" from the HM-cohort $(46 / 247,18.6 \%)$ to the LR-cohort (131/701, 18.6\%).

\section{Additional files}

Additional file 1: Table S1. BMP antagonist expression in CD138+ purified cells. Bold indicates differential expression in MM compared to healthy donor bone marrow plasma cells (BMPCs).

Additional file 2: Table S2. BMP antagonist expression pattern in whole bone marrow (WBM) samples. Bold indicates differential expression.

Additional file 3: Figure S1. EFS and OS in the LR cohort when the same fraction of patients defined as "high" IGFBP7 expressers in the HMcohort (18.6\%) was designated as high expressers in the LR-cohort. High IGFBP7 expression was associated with adverse event-free $(P<0.001)$ and overall survival $(P<0.002)$ by applying this criterion.

Additional file 4: Figure S2. IGFBP7 expression is associated with high risk cytogenetics. Gene expression analysis of the HM-patient cohort revealed that high IGFBP7 expression levels were associated with poor risk cytogenetic markers including (A) translocation $t(4 ; 14)$ and $(C)$ amplification 1q21. Moreover, a trend was found regarding the more frequent presence of deletion $13 q$ in patients with high /GFBP7 expression values (D). No association 
was observed for (B) translocation $\mathrm{t}(11 ; 14)$ and $(\mathrm{E})$ deletion 17p. Grey data points indicate an absent, black data points a present Affymetrix detection call.

Additional file 5: Figure S3. IGFBP7 expression is elevated in MMSET defined molecular subgroups of myeloma. IGFBP7 expression was analysed in two publically available GEP datasets published by (A) Zhan et al. [33] and (B) Agnelli et al. [34]. Both datasets classified MM cases into distinct molecular subgropus based on microarray experiments. (A) IGFBP7 expression was significantly elevated in the MMSET (MS) overexpressing subgroup compared to five other GEP-defined subgroups. In addition, IGFBP7 expression tended to be elevated in the MS subgroup compared to the $t(1 ; 14)$ associated cyclin D1 (CD1) overexpressing samples. The other subgoups were defined by a proliferation (PR), low bone involvement (LB), hyperdiploid (HY), $t(6 ; 14)$ associated cyclin D (CD2) and MAF (MF) expression based GEP profile. (B) Analysis of the dataset from Agnelli et al. [34] confirmed overexpression of IGFBP7 in the MMSET defined molecular subgroup of MM (TC4). The other subgroups were defined by cyclin D overexpression (TC1), hyperdiploid status (TC2) and MAF overexpression (TC5.) TC3 was defined by the lack of association with any of the other subgroups. Asterisks indicate statistical significance compared with the other molecular subgroups $(* P<0.05)$. Horizontal lines represent median IGFBP7 expression with interquartile range.

\section{Abbreviations}

ALL: acute lymphoblastic leukemia; aza: 5-aza-2'-deoxcytidine; BM: bone marrow; BMP: bone morphogenetic protein; BMSC: bone marrow stromal cell; EFS: event-free survival; DKK-1: Dickkopf 1; GEP: gene expression profiling; GPI: GEP-based proliferation index; HMCL: human myeloma cell line; IGF-1: insulin like growth factor 1; IGFBP7: Insulin like growth factor binding protein 7; MBC: memory B cell; MGUS: monoclonal gammopathy of undetermined significance; MM: multiple myeloma; MMSET: multiple myeloma SET domain; OS: overall survival; PC: plasma cell; PPC: polyclonal plasmablastic cell; TSA: trichostatin A; VEGF: vascular endothelial growth factor.

\section{Competing interests}

The authors declare that they have no competing interests.

\section{Authors' contributions}

$A B, D H, N Z, H L$ and $B K$ designed the research. AB performed the experiments. AS, SL, DH and BK performed gene expression profiling and analysed the data. $A B, M S, D H e$ and $D H$ performed the statistical analysis. $A B$, $\mathrm{DH}$ and NZ wrote the paper. All authors reviewed and approved the final version of the manuscript.

\section{Acknowledgments}

This work was supported by a grant from the Fellinger Krebsforschungsverein and the Austrian Forum against Cancer, as well as in part by grants from the Deutsche Forschungsgemeinschaft (SFB/TRR79), and the Bundesministerium für Bildung und Forschung (CAMPSIMM and CLIOMMICS), Bonn, Germany. The funders had no role in study design, data collection and analysis, preparation of the manuscript as well as decision to publish.

The authors would like to thank Elsa Thagian for excellent technical assistance.

\section{Author details}

'Wilhelminen Cancer Research Institute, Department of Internal Medicine I, Wilhelminenspital, Montleartstraße 37, 1160 Vienna, Austria. ${ }^{2}$ Medizinische Klinik V, Universitaetsklinikum Heidelberg, Heidelberg, Germany. ${ }^{3}$ INSERM U1040, Institute for Research in Biotherapy, CHU Montpellier, Hospital St Eloi, Montpellier, France.

\section{Received: 25 August 2014 Accepted: 30 December 2014}

\section{Published online: 08 February 2015}

\section{References}

1. Palumbo A, Anderson KC. Multiple myeloma. N Engl J Med. 2011;364:1046-60.

2. Mahtouk K, Moreaux J, Hose D, Rème T, Meissner T, Jourdan M, et al. Growth factors in multiple myeloma: a comprehensive analysis of their expression in tumor cells and bone marrow environment using Affymetrix microarrays. BMC Cancer. 2010;10:198.
3. Moreaux J, Hose D, Kassambara A, Reme T, Moine P, Requirand G, et al. Osteoclast-gene expression profiling reveals osteoclast derived CCR2 chemokines promoting myeloma cell migration. Blood. 2011;117:1280-90.

4. Corre J, Mahtouk K, Attal M, Gadelorge M, Huynh A, Fleury-Cappellesso S, et al. Bone marrow mesenchymal stem cells are abnormal in multiple myeloma. Leukemia. 2007;21:1079-88.

5. Klein B, Zhang XG, Jourdan M, Content J, Houssiau F, Aarden L, et al. Paracrine rather than autocrine regulation of myeloma-cell growth and differentiation by interleukin-6. Blood. 1989;73:517-26.

6. Sprynski AC, Hose D, Caillot L, Reme T, Shaughnessy Jr JD, Barlogie B, et al. The role of IGF-1 as a major growth factor for myeloma cell lines and the prognostic relevance of the expression of its receptor. Blood. 2009;113:4614-26

7. Sprynski AC, Hose D, Kassambara A, Vincent L, Jourdan M, Rossi JF, et al. Insulin is a potent myeloma cell growth factor through insulin/IGF-1 hybrid receptor activation. Leukemia. 2010;24:1940-50.

8. Pearse RN, Sordillo EM, Yaccoby S, Wong BR, Liau DF, Colman N, et al. Multiple myeloma disrupts the TRANCE/osteoprotegerin cytokine axis to trigger bone destruction and promote tumor progression. Proc Natl Acad Sci U S A. 2001;98:11581-6.

9. Tian E, Zhan F, Walker R, Rasmussen E, Ma Y, Barlogie B, et al. The role of the Wnt-signaling antagonist DKK1 in the development of osteolytic lesions in multiple myeloma. N Engl J Med. 2003;349:2483-94.

10. Vallet S, Mukherjee S, Vaghela N, Hideshima T, Fulciniti M, Pozzi S, et al. Activin A promotes multiple myeloma-induced osteolysis and is a promising target for myeloma bone disease. Proc Natl Acad Sci U S A. 2010;107:5124-9.

11. Lin GL, Hankenson KD. Integration of BMP, Wnt, and notch signaling pathways in osteoblast differentiation. J Cell Biochem. 2011;112:3491-501.

12. Holien $T$, Vătsveen TK, Hella $H$, Rampa C, Brede G, Grøseth LA, et al. Bone morphogenetic proteins induce apoptosis in multiple myeloma cells by Smad-dependent repression of MYC. Leukemia. 2012;26:1073-80.

13. Seckinger A, Meissner T, Moreaux J, Goldschmidt H, Fuhler GM, Benner A, et al. Bone morphogenic protein 6 : a member of a novel class of prognostic factors expressed by normal and malignant plasma cells inhibiting proliferation and angiogenesis. Oncogene. 2009;28:3866-79.

14. Sneddon JB, Zhen HH, Montgomery K, van der Rijn M, Tward AD, West R, et al. Bone morphogenetic protein antagonist gremlin 1 is widely expressed by cancer-associated stromal cells and can promote tumor cell proliferation. Proc Natl Acad Sci U S A. 2006;103:14842-7.

15. Yamanaka $Y$, Wilson EM, Rosenfeld RG, Oh Y. Inhibition of insulin receptor activation by insulin-like growth factor binding proteins. J Biol Chem. 1997;272:30729-34.

16. Tamura K, Hashimoto K, Suzuki K, Yoshie M, Kutsukake M, Sakurai T. Insulinlike growth factor binding protein-7 (IGFBP7) blocks vascular endothelial cell growth factor (VEGF)-induced angiogenesis in human vascular endothelial cells. Eur J Pharmacol. 2009;610:61-7.

17. Kato MV. A secreted tumor-suppressor, mac25, with activin-binding activity. Mol Med. 2000;6:126-35.

18. Esterberg R, Delalande JM, Fritz A. Tailbud-derived Bmp4 drives proliferation and inhibits maturation of zebrafish chordamesoderm. Development. 2008:153:3891-901.

19. Wajapeyee N, Serra RW, Zhu X, Mahalingam M, Green MR. Oncogenic BRAF induces senescence and apoptosis through pathways mediated by the secreted protein IGFBP7. Cell. 2008;132:363-74.

20. Chen Y, Pacyna-Gengelbach M, Ye F, Knösel T, Lund P, Deutschmann N, et al. Insulin-like growth factor binding protein-related protein 1 (IGFBP-rP1) has potential tumour-suppressive activity in human lung cancer. J Pathol. 2007:211:431-8.

21. Smith P, Nicholson L, Syed N, Payne A, Hiller L, Garrone O, et al. Epigenetic Inactivation Implies Independent Functions for Insulin-like Growth Factor Binding Protein (IGFBP) - Related Protein 1 and the Related IGFBPL1 in Inhibiting Breast Cancer Phenotypes. Clin Cancer Res. 2007;13:4061-68.

22. An W, Ben QW, Chen HT, Zheng JM, Huang L, Li GX, et al. Low expression of IGFBP7 is associated with poor outcome of pancreatic ductal adenocarcinoma. Ann Surg Oncol. 2012;19:3971-8.

23. Tomimaru Y, Equchi H, Wada H, Kobayashi S, Marubashi S, Tanemura M, et al. IGFBP7 downregulation is associated with tumor progression and clinical outcome in hepatocellular carcinoma. Int J Cancer. 2012;130:319-27.

24. Smith E, Ruszkiewicz AR, Jamleson GG, Drew PA. IGFBP7 is associated with poor prognosis in oesophageal adenocarcinoma and is regulated by promoter DNA methylation. Br J Cancer. 2014;110:775-82. 
25. Sepiashvili L, Hui A, Ignatchenko V, Shi W, Su S, Xu W, et al. Potentially novel candidate biomarkers for head and neck squamous cell carcinoma identified using an integrated cell line-based discovery strategy. Mol Cell Proteomics. 2012;11:1404-15.

26. Heesch S, Schlee C, Neumann M, Stroux A, Kühnl A, Schwartz S, et al. BAALC-associated gene expression profiles define IGFBP7 as a novel molecular marker in acute leukemia. Leukemia. 2010;24:1429-36.

27. Laranjeira $A B$, de Vasconcellos JF, Sodek L, Spago MC, Fornazim MC, Tone $L G$, et al. IGFBP7 participates in the reciprocal interaction between acute lymphoblastic leukemia and BM stromal cell and in leukemia resistance to asparaginase. Leukemia. 2012;26:1001-11.

28. Zhan F, Huang Y, Colla S, Stewart JP, Hanamura I, Gupta S, et al. The molecular classification of multiple myeloma. Blood. 2006;108:2020-8.

29. Agnelli L, Bicciato S, Mattioli M, Fabris S, Intini D, Verdelli D, et al. Molecular classification of multiple myeloma: a distinct transcriptional profile characterizes patients expressing CCND1 and negative for $14 \mathrm{q} 32$ translocations. J Clin Oncol. 2005;23:7296-306.

30. Sullivan L, Murphy TM, Barret C, Loftus B, Thornhill J, Lawler M, et al. IGFBP7 promoter methylation and gene expression analysis in prostate cancer. J Urol. 2012;188:1354-60

31. Chen Y, Cui T, Knösel T, Yang L, Zöller K, Petersen I. IGFBP7 is a p53 target gene inactivated in human lung cancer by DNA hypermethylation. Lung Cancer. 2004;73:38-44.

32. Heesch S, Bartram I, Neumann M, Reins J, Mossner M, Schlee C, et al. Expression of IGFBP7 in acute leukemia is regulated by DNA methylation. Cancer Sci. 2011;102:253-9.

33. Mohan S, Baylink DJ. IGF-binding proteins are multifunctional and act via IGFdependent and -independent mechanisms. J Endocrinol. 2002;175:19-31.

34. Oh Y, Nagalla SR, Yamanaka Y, Kim HS, Wilson E, Rosenfeld RG. Synthesis and characterization of insulin-like growth factor-binding protein (IGFBP)-7. Recombinant human mac25 specifically binds IGF-I and -II. J Biol Chem. 1996:271:30322-5.

35. Chen D, Yoo BK, Santhekadur PK, Gredler R, Bhutia SK, Das SK, et al. Insulinlike growth factor-binding protein-7 functions as a potential tumor suppressor in hepatocellular carcinoma. Clin Cancer Res. 2011;17:6693-701.

36. Vizioli MG, Sensi M, Miranda C, Cleris L, Formelli F, Anania MC, et al. IGFBP7: an oncosuppressor gene in thyroid carcinogenesis. Oncogene. 2010;29:3835-44

37. Sato Y, Chen Z, Miyazaki K. Strong suppression of tumor growth by insulinlike growth factor-binding protein-related protein 1/tumor-derived cell adhesion factor/mac25. Cancer Sci. 2007;98:1055-63.

38. Amemiya Y, Yang W, Benatar T, Nofech-Mozes S, Yee A, Kahn H, et al. Insulin like growth factor binding protein-7 reduces growth of human breast cancer cells and xenografted tumors. Breast Cancer Res Treat. 2012;133:563-73.

39. Jiang W, Xiang C, Cazacu S, Brodie C, Mikkelsen T. Insulin-like growth factor binding protein 7 mediates glioma cell growth and migration. Neoplasia. 2008;10:1335-42

40. Pen A, Moreno MJ, Durocher Y, Deb-Rinker P, Stanimirovic DB. Glioblastomasecreted factors induce IGFBP7 and angiogenesis by modulating Smad-2dependent TGF-beta signaling. Oncogene. 2008;27:6834-44.

41. Rupp C, Scherzer M, Rudisch A, Unger C, Haslinger C, Schweifer N, et al. IGFBP7, a novel tumor stroma marker, with growth-promoting effects in colon cancer through a paracrine tumor-stroma interaction. Oncogene 2014; [Epub ahead of print].

42. Hose D, Moreaux J, Meissner T, Seckinger A, Goldschmidt H, Benner A, et al. Induction of angiogenesis by normal and malignant plasma cells. Blood. 2009;114:128-43.

43. Hose D, Rème T, Meissner T, Moreaux J, Seckinger A, Lewis J, et al. Inhibition of aurora kinases for tailored risk-adapted treatment of multiple myeloma. Blood. 2009;113:4331-40.

44. Seckinger A, Meissner T, Moreaux J, Depeweg D, Hillengass J, Hose K, et al. Clinical and prognostic role of annexin A2 in multiple myeloma. Blood. 2012;120:1087-94.

45. Martinez-Garcia E, Popovic R, Min DJ, Sweet SM, Thomas PM, Zamdborg L, et al. The MMSET histone methyl transferase switches global histone methylation and alters gene expression in $\mathrm{t}(4 ; 14)$ multiple myeloma cells. Blood. 2011;117:211-20.

46. Lopez-Bermejo A, Koshravi J, Fernandez-Real JM, Hwa V, Pratt KL, Casamitjana $\mathrm{R}$, et al. Insulin resistance is associated with increased serum concentration of IGF-binding protein-related protein 1 (IGFBP-rP1/MAC25). Diabetes. 2006;55:2333-9.
47. Chantry AD, Heath D, Mulivor AW, Pearsall S, Baud'huin M, Coulton L, et al. Inhibiting activin-A signalling stimulates bone formation and prevents cancerinduced bone destruction in vivo. J Bone Miner Res. 2010;25:2633-46.

48. Robbiani DF, Chesi M, Bergsagel PL. Bone lesions in molecular subtypes of multiple myeloma. N Engl J Med. 2004;351:197-8.

49. Jourdan M, Caraux A, De Vos J, Fiol G, Larroque M, Cognot C, et al. An in vitro model of differentiation of memory $B$ cells into plasmablasts and plasma cells including detailed phenotypic and molecular characterization. Blood. 2009;114:5173-81.

50. Barlogie B, Tricot G, Rasmussen E, Anaissie E, van Rhee F, Zangari M, et al. Total therapy 2 without thalidomide in comparison with total therapy 1 : role of intensified induction and posttransplantation consolidation therapies. Blood. 2006;107:2633-8.

51. van Rhee F, Szymonifka J, Anaissie E, Nair B, Waheed S, Alsayed Y, et al. Total Therapy 3 for multiple myeloma: prognostic implications of cumulative dosing and premature discontinuation of VTD maintenance components, bortezomib, thalidomide, and dexamethasone, relevant to all phases of therapy. Blood. 2010;116:1220-7.

52. Neben $\mathrm{K}$, Jauch $\mathrm{A}$, Hielscher $\mathrm{T}$, Hillengass J, Lehners $\mathrm{N}$, Seckinger $\mathrm{A}$, et al. Progression in smoldering myeloma is independently determined by the chromosomal abnormalities del(17p), t(4;14), gain 1q, hyperdiploidy, and tumor load. J Clin Oncol. 2013;31:4325-32.

53. Warren P, Taylor D, Martini PGV, JAckson J, Bienkowska J. PANP - a New Method of Gene Detection on Oligonucleotide Expression Arrays. Bioinformatics and Bioengineering, 2007 BIBE 2007. Proceedings of the 7th IEEE International Conference on 14-17 Oct 2007. 2007;108-15.

\section{Submit your next manuscript to BioMed Central and take full advantage of:}

- Convenient online submission

- Thorough peer review

- No space constraints or color figure charges

- Immediate publication on acceptance

- Inclusion in PubMed, CAS, Scopus and Google Scholar

- Research which is freely available for redistribution 